\title{
Comparison of Different Microwave Digestion Methods for Heavy Metals from Stream Sediment
}

\author{
Zhenzhen Qiu ${ }^{1, a}$, Jingdong Zhang ${ }^{1, b^{*}}$, Chaoyang $\mathrm{Liu}^{1, \mathrm{c}}$, Fei $\mathrm{Li}^{1, \mathrm{~d}}$, Zixian $\mathrm{Wu}^{1, \mathrm{e}}$ \\ Research Center for Environment and Health, Zhongnan University of Economics and Law, \\ Wuhan 430073, China

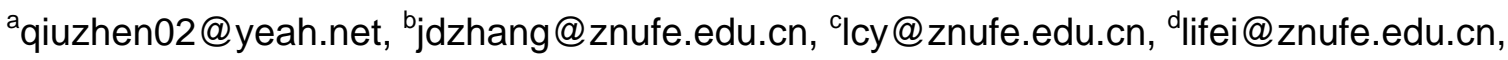 \\ ewuzixianjia@163.com
}

*Corresponding authors: Jingdong Zhang

Keywords: Stream sediment, heavy mental, microwave digestion, GFAAS.

Abstract. Appropriate digestion of environmental sample, including soil, sediment and dust, plays a key step in their total heavy metal detection. In order to explore the optimized digestion method, 8 kinds of commonly used hybrid acids groups were selected to simultaneously detect total concentrations of $\mathrm{Pb}$ and $\mathrm{Cd}$ in stream sediment using microwave digestion instrument. The result showed that method $6 \mathrm{HNO}_{3}+2 \mathrm{HCl}+2 \mathrm{HF}, 8 \mathrm{HNO}_{3}+4 \mathrm{HCl}+4 \mathrm{HF}, 5 \mathrm{HNO}_{3}+2 \mathrm{HClO}_{4}+8 \mathrm{HF}$ had better digestion effects than others through the comparison of digestion solutions. Furthermore, the detection result based on $6 \mathrm{HNO}_{3}+2 \mathrm{HCl}+2 \mathrm{HF}$ was basically in the range of standard reference value GBW07310. The average concentrations of $\mathrm{Pb}$ and Cd were $23.44 \mathrm{mg} / \mathrm{kg}$ and $1.045 \mathrm{mg} / \mathrm{kg}$, while the effectiveness of detection results using the other two methods were quite difference with reference value. Therefore, hybrid acids group $6 \mathrm{HNO}_{3}+2 \mathrm{HCl}+2 \mathrm{HF}$ was identified as the best digestion method in this study.

\section{Introduction}

Heavy metals are pollutants with great potential risk [1], which are in common existence in sediment, soil, dust etc. $[2,3,4]$ In addition, heavy metals are difficult to be detected only if they are digested. However, the most recent standardization of digestion method was published in 1997 without updating in the past two decades [5]. Some reports have been published on the study of digestion methods in recent years. Jian Chen chose method $6.4 \mathrm{HNO}_{3}+2.5 \mathrm{HF}$ to detect total concentration of heavy metals, and found it was a method quite adequate for majority heavy metals [6]. Huilan Jian selected $\mathrm{HNO}_{3}-\mathrm{HCl}-\mathrm{H}_{2} \mathrm{O}_{2}$ to digest marine sediment with satisfactory results [7]. Shuxuan Ling detected the concentration of 9 heavy metals in stream sediment with digestion system $\mathrm{HNO}_{3}-\mathrm{H}_{2} \mathrm{O}_{2}$ - $\mathrm{HF}$ [8]. Although many researchers have studied in this filed, there is still no unified conclusion on optimized digestion method. In summary, it has great significance to compare commonly used methods and determine an optimal method. In present study, we explored the optimized digestion method by comparing 8 kinds of commonly used hybrid acids groups.

The objectives of this study were (i) to determine which hybrid acids group has the best digestion effect based on state of digestion solutions, (ii) to identify the best method for detecting concentration of heavy metals.

\section{Materials and Methods}

Instruments and Reagents. TOPWave microwave digestion instrument, ZEEnit-700P Atomic Absorption Spectrometer, electric heating plate, PTFE crucible, Standard Reference Stream Sediment GBW07310, Soil Reference Materials GSS-5 [9], self-collected soil, standard materials Pb, $\mathrm{Cd}$ (1000 mg/L), $\mathrm{HNO}_{3}, \mathrm{HF}, \mathrm{H}_{2} \mathrm{O}_{2}, \mathrm{HCl}, \mathrm{NH}_{4} \mathrm{H}_{2} \mathrm{PO}_{4}$.

Sample Preparation. A large amount of hybrid-acids recipes were used in microwave digestion. $\mathrm{HNO}_{3}$ was used to decompose organic matter in the samples usually, which had better digestion effects while cooperates with $\mathrm{HF}$ or $\mathrm{H}_{2} \mathrm{O}_{2}$ [10]. Wangmin used $\mathrm{HCl}$ and $\mathrm{HNO}_{3}$ to digested stream 
sediment, and found that $\mathrm{HCl}$ also could improve the digestion effect of $\mathrm{HNO}_{3}$ [11]. $\mathrm{HF}$ was often used in the decomposition of samples containing silicon and silicate [10].

In order to investigate the digestion effects of different hybrid acids groups, 8 hybrid acids groups were selected based on a large number of articles and literatures, respectively, $a .6 \mathrm{HNO}_{3}+2 \mathrm{HCl}+2 \mathrm{HF}$, b. $\mathrm{HNO}_{3}+4 \mathrm{HCl}+4 \mathrm{HF}, c .6 \mathrm{HNO}_{3}+3 \mathrm{HCl}+3 \mathrm{HF}, d .3 \mathrm{HNO}_{3}+9 \mathrm{HCl}+2 \mathrm{HF}, e .5 \mathrm{HNO}_{3}+4 \mathrm{H}_{2} \mathrm{O}_{2}+1 \mathrm{HF}, f$. $4 \mathrm{HNO}_{3}+4 \mathrm{H}_{2} \mathrm{O}_{2}+3 \mathrm{HF}, g .4 \mathrm{HNO}_{3}+2 \mathrm{HCl}, h$. $5 \mathrm{HNO}_{3}+2 \mathrm{HClO}_{4}+8 \mathrm{HF}$. The temperature program of microwave digestion instrument was presented in Table 1.

Table 1 The temperature program of microwave digestion

\begin{tabular}{ccc}
\hline Ramp time $[\mathrm{min}]$ & Digestion time $\left[{ }^{\circ} \mathrm{C}\right]$ & Holding time $[\mathrm{min}]$ \\
\hline 7 & 120 & 3 \\
5 & 160 & 3 \\
5 & 180 & 25 \\
- & Finish & 15
\end{tabular}

Detection Conditions. Trace elements $\mathrm{Pb}$ and $\mathrm{Cd}$ in stream sediment were detected by GFAAS (Graphite Furnace Atomic Absorption Spectrometer), and the specific heating program was shown in Table 2.

Table 2 The operating conditions of GFAAS

\begin{tabular}{lllllllll}
\hline \multirow{2}{*}{ Process } & \multicolumn{3}{c}{$\begin{array}{c}\text { Start temperature } \\
{\left[{ }^{\circ} \mathrm{C}\right]}\end{array}$} & \multicolumn{2}{c}{$\begin{array}{l}\text { Ramp } \\
{\left[{ }^{\circ} \mathrm{C} / \mathrm{min}\right]}\end{array}$} & \multicolumn{2}{c}{$\begin{array}{c}\text { Holding time } \\
{[\mathrm{min}]}\end{array}$} & \multicolumn{2}{c}{ Total time } \\
& $\mathrm{Pb}$ & $\mathrm{Cd}$ & $\mathrm{Pb}$ & $\mathrm{Cd}$ & $\mathrm{Pb}$ & $\mathrm{Cd}$ & $\mathrm{Pb}$ & $\mathrm{Cd}$ \\
\hline Drying & 80 & 80 & 6 & 6 & 20 & 20 & 28.3 & 28.3 \\
Drying & 90 & 90 & 3 & 3 & 20 & 20 & 23.3 & 23.3 \\
Drying & 110 & 110 & 5 & 5 & 10 & 10 & 14 & 14 \\
Ashing & 350 & 800 & 50 & 50 & 20 & 20 & 24.8 & 33.8 \\
Ashing & 900 & - & 300 & - & 10 & - & 11.8 & - \\
Zero reset & 900 & 800 & 0 & 0 & 6 & 6 & 6 & 6 \\
Atomization & 1350 & 1150 & 1400 & 1500 & 4 & 3 & 4.3 & 3 \\
Residue removal & 2450 & 2450 & 500 & 500 & 4 & 4 & 6.2 & 4 \\
\hline
\end{tabular}

\section{Results and Discussion}

Analysis of Digestion Effects. As the results shown in Table 3, the color of the solutions digested by different hybrid acids were different. Digestion system $\mathrm{HNO}_{3}-\mathrm{HCl}-\mathrm{HF}, \mathrm{HNO}_{3}-\mathrm{HCl}$ and $\mathrm{HNO}_{3}-\mathrm{HClO}_{4}$-HF presented pale yellow, while the color of system $\mathrm{HNO}_{3}-\mathrm{H}_{2} \mathrm{O}_{2}$ - $\mathrm{HF}$ was crystal clear. In addition, though the proportion of acids was different in the system $\mathrm{HNO}_{3}-\mathrm{HCl}-\mathrm{HF}$, the digestion for samples was quite complete. Furthermore, when $\mathrm{HNO}_{3}: \mathrm{HCl}: \mathrm{HF}=2: 1: 1$, the digestion effect was the best in all situations. Besides, digestion system $\mathrm{HNO}_{3}-\mathrm{HClO}_{4}-\mathrm{HF}$ was pretty good, either. The effect was not desirable due to there was a little residue left while samples digested with system $\mathrm{HNO}_{3}-\mathrm{H}_{2} \mathrm{O}_{2}-\mathrm{HF}$. The digestion system $\mathrm{HNO}_{3}-\mathrm{HCl}$ mentioned in a literature which was considered as a great digestion method that was also tried, but the effect was under reconsideration. The result of system $\mathrm{HNO}_{3}-\mathrm{HCl}$ indicated that it's different to digest sediment completely without $\mathrm{HF}$ [8].

Due to the relative characteristic nature of soil and stream sediment, hybrid acids group $6 \mathrm{HNO}_{3}+2 \mathrm{HCl}+2 \mathrm{HF}$, which was confirmed had good digestion effect, was used to digest yellow-red soil (GSS-5) and self-collected soil. Digestion effects for soil and sediment were different even with the same digestion method (Table 3). Therefore, there were difference between stream sediment and soil in hybrids acids choosing.

In brief, digestion system $\mathrm{HNO}_{3}-\mathrm{HCl}-\mathrm{HF}$ and $\mathrm{HNO}_{3}-\mathrm{HClO}_{4}-\mathrm{HF}$ had better effects than others, and there were differences between stream sediment and soil in optimized digestion method. 
Table 3 The evaluation of digestion effects

\begin{tabular}{|c|c|c|}
\hline $\begin{array}{l}\text { Number of adopted } \\
\text { hybrid acids groups }\end{array}$ & Samples & Digestion effects \\
\hline$a$ & GBW07310 & $\begin{array}{l}\text { The solution was pale yellow without residue, } \\
\text { digestion was complete. }\end{array}$ \\
\hline$b$ & GBW07310 & $\begin{array}{l}\text { The solution was pale yellow without residue, } \\
\text { digestion was complete. }\end{array}$ \\
\hline c & GBW07310 & $\begin{array}{l}\text { The solution was pale yellow without obvious residue, } \\
\text { digestion was relatively complete. }\end{array}$ \\
\hline$d$ & GBW07310 & $\begin{array}{l}\text { The solution was pale yellow without obvious residue, } \\
\text { digestion was relatively complete. }\end{array}$ \\
\hline$e$ & GBW07310 & $\begin{array}{l}\text { The solution was crystal clear with a little residue, } \\
\text { digestion wasn't complete. }\end{array}$ \\
\hline$f$ & GBW07310 & $\begin{array}{l}\text { The solution was crystal clear with a little residue, } \\
\text { digestion wasn't complete. }\end{array}$ \\
\hline$g$ & GBW07310 & $\begin{array}{l}\text { The solution was crystal clear with a little residue, } \\
\text { digestion wasn't complete. }\end{array}$ \\
\hline$h$ & GBW07310 & $\begin{array}{l}\text { The solution was pale yellow without residue, } \\
\text { digestion was complete. }\end{array}$ \\
\hline$a$ & GSS-5 & $\begin{array}{l}\text { The solution was pale yellow without obvious residue, } \\
\text { digestion was relatively complete. }\end{array}$ \\
\hline$a$ & $\begin{array}{l}\text { Self-collected } \\
\text { soil }\end{array}$ & $\begin{array}{l}\text { The solution was pale yellow with a lot of residue, } \\
\text { digestion wasn't complete. }\end{array}$ \\
\hline
\end{tabular}

Analysis of Detection Results. In order to seek which proportion of hybrid acids could make the best digestion effect, aforementioned hybrid acids groups $a, b, h$ were selected to make a series of experiments.

The detection contents of $a$ were basically in the range of standard reference value, for the mean content of $\mathrm{Pb}$ was $23.44 \mathrm{mg} / \mathrm{kg}$, Cd was $1.045 \mathrm{mg} / \mathrm{kg}$, while the standard reference value of $\mathrm{Pb}$, Cd were $25-29 \mathrm{mg} / \mathrm{kg}$ and $1.04-1.20 \mathrm{mg} / \mathrm{kg}$, respectively (Fig. 1). As for method $b$, the content of $\mathrm{Pb}$ was basically in the range while $\mathrm{Cd}$ was a little lower than reference value. Method $h$ was the worst for the content of $\mathrm{Pb}$ was lower than reference value, but $\mathrm{Cd}$ was much higher. In terms of standard deviation, value of $\mathrm{Pb}$ with method $h$ was much higher than others, although $h$ has minimum standard deviation value of $\mathrm{Cd}$. Therefore, hybrid acids group $6 \mathrm{HNO}_{3}+2 \mathrm{HCl}+2 \mathrm{HF}$ was identified as the best digestion.

\section{Improvement}

The present research had great significance for digestion of environmental sample such as sediment and soil, but it had some shortcomings. Limited by experimental conditions, experimental data were not sufficient, so more repeated experiments should be done in the future. In addition, only hybrid acids group $a$ was chosen to confirm that optimized digestion method for sediment and soil was different. Moreover, due to the causes of operation, reagents and so on, standard deviation of detection results need to be improved.

\section{Conclusions}

The research explored the optimized digestion method for heavy metals through the comparison of 8 kinds of hybrid acids groups. The result showed that methods $a, b, h$ had better digestion effects than 


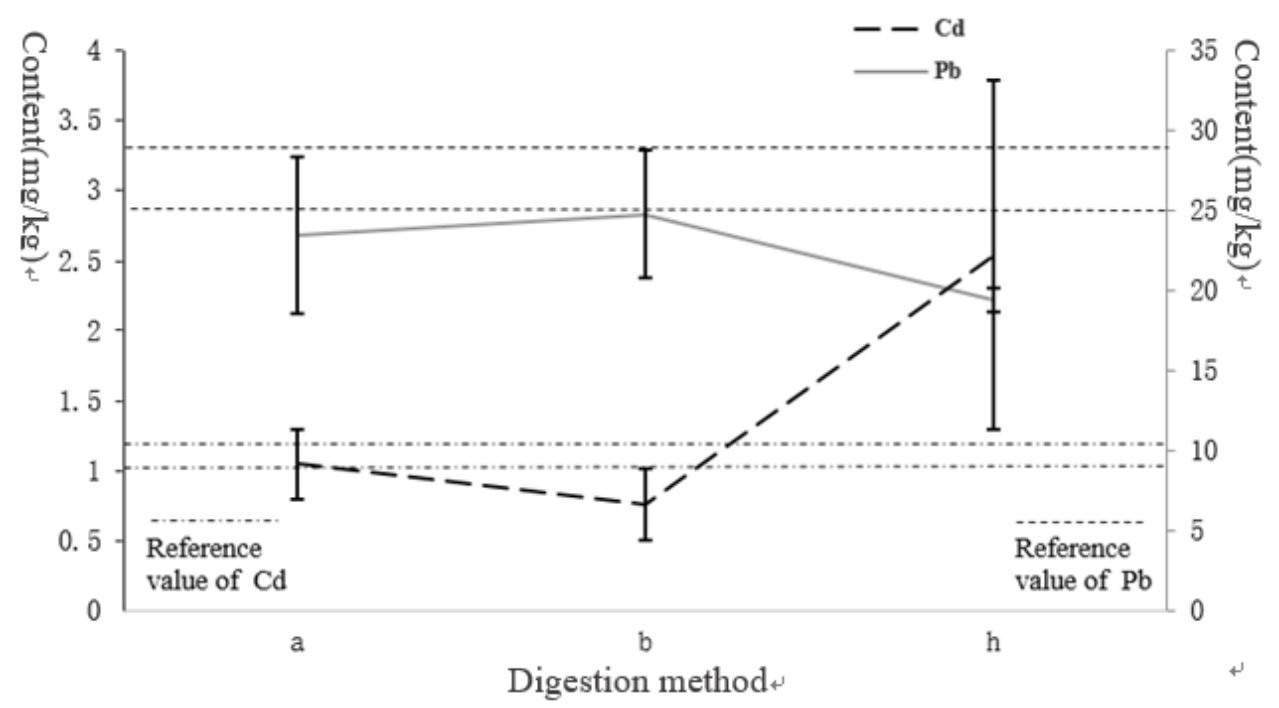

Fig. 1 The detection results of $\mathrm{Pb}$, Cd with different digestion methods

others by the state of digestion solutions. For sediment and soil, digestion effects were distinguishing even with the same digestion method. In addition, hybrid acids group $6 \mathrm{HNO}_{3}+2 \mathrm{HCl}+2 \mathrm{HF}$ obtained the best digestion effect. Because the detection results of this method were basically in the range of reference values, and standard deviation of $\mathrm{Pb}$, Cd were 4.908 and 0.244 , respectively. However, the results of $\mathrm{HNO}_{3}+4 \mathrm{HCl}+4 \mathrm{HF}$ and $5 \mathrm{HNO}_{3}+2 \mathrm{HClO}_{4}+8 \mathrm{HF}$ were far from expected. In a word, hybrid acids group $6 \mathrm{HNO}_{3}+2 \mathrm{HCl}+2 \mathrm{HF}$ was suitable for microwave digestion of stream sediment.

\section{References}

[1] C.Y. Liu, C.B. Chi, K.Q. Ye: Transl Neurodegener. (2016)， DOI: 10.1186/s40035-015-0048-7

[2] F. Li, J.H. Huang and G.M. Zeng: J Geochem Explor. Forum Vol. 132 (2013), p. 75-83

[3] J. Huang, F. Li and G. Zeng: Sci Total Environ. Forum Vol. 541 (2016), p. 969-976

[4] F. Li, J.D. Zhang and J.H. Huang: Environ Sci Pollut Res. (2016), DOI: 10.1007/s11356-016-6458-y

[5] Ministry of Environmental Protection of the People's Republic of China, Soil quality-Determination of lead, cadmium-Graphite furnace atomic absorption spectrophotometry, GB/T 17141-1997.

[6] J. Chen, J.B. Liao and C.H. Wei: Chinese J Anal Lab. Forum Vol. 33 (2014), p. 803-807 (In Chinses)

[7] H.L. Jian, X.Q. Yin and J.F. Zhang: Chinese J Spectrosc Lab. Forum Vol. 24 (2007), p. 138-141 (In Chinses)

[8] S.X. Liang, X. Wang and H. Wu: Spectrosc Spect Anal. Forum Vol. 32 (2012), p. 809-812 (In Chinses)

[9] F. Li, J.H. Huang and G.M. Zeng: Hum Ecol Risk Assess. Forum Vol. 20 (2014), p. $1213-1230$

[10] M. R. Ghanbarpour, M. Goorzadi and G. Vahabzade: Sustain Water Qual Ecol. Forum Vol. 1-2 (2014), p. 48-58

[11] M. Wang, C.H. Zhao and Q. Zhang: Anhui Agr Sci. Forum Vol. 16 (2012), p. 7128-7129 (In Chinses) 